\title{
ANALISA DETEKSI GAMBAR TERMODIFIKASI DENGAN DEVIASI PIXEL
}

\author{
Heriyanto \\ Jurusan Teknik Informatika UPN "Veteran" Yogyakarta \\ JI. Babarsari 2 Tambakbayan 55281 Telp (0274) 485323 \\ e-mail : mr heriyanto skom@yahoo.com
}

\begin{abstract}
Picture which used many to a collection by otentifikasi make a document which is very worth which can be kept depicting aktifitas or a memory and remind will event. Depository of picture can in the form of bitmap file represent a text file document in the form of bmp, jpeg. All most picture can modify with processing return by expurgation in the form of renewing contrast, modification and also colour trigging up picture or photo with a purpose to do editing so that some part which is not fair become is better. Pemodifikasian draw in general to do the photo appearance become better but sometimes the existence of some importance to modify picture or photo for the sake of other like modifying photo and picture for the things of which is negative take example to change face picture or body one with body or picture or other shares which non part of the photo so that with modified by negative for the purpose of harming and even photograph pornography which is many in modification for the purpose of certain so that many victim.
\end{abstract}

\section{Keywords : Picture, Bitmap, Modification, Photo, Contras}

Gambar yang banyak digunakan untuk suatu koleksi secara otentifikasi menjadikan suatu dokumen yang sangat berharga yang dapat disimpan yang menggambarkan aktifitas atau suatu kenangan dan mengingatkan akan suatu peristiwa. Penyimpanan gambar dapat berupa file bitmap merupakan suatu dokumen file teks berupa bmp, jpeg. Pada kebanyakan gambar dapat dilakukan modifikasi atau melakukan pengolahan kembali dengan melakukan pengeditan berupa memperbarui kontras, warna maupun modifikasi yang memperbagus tampilan gambar/foto dengan tujuan melakukan editing agar beberapa bagian yang tidak cerah menjadi lebih baik. Pemodifikasian gambar pada umumnya untuk melakukan perbaikamn agar tampilan foto tersebut menjadi lebih baik namun terkadang adanya beberapa kepentingan untuk memodifikasi foto atau gambar untuk kepentingan lain seperti memodifikasi gambar dan foto untuk hal-hal yang negative misalkan mengganti gambar wajah atau tubuh seseorang dengan gambar atau tubuh atau bagian lain yang bukan bagian dari foto tersebut sehingga dengan termodifikasi secara negative untuk tujuan yang merugikan dan bahkan foto pornografi yang banyak di modifikasi untuk tujuan tertentu sehingga banyak korban yang menjadi sasaran.

Kata kunci : gambar, bitmap, modifikasi,foto,kontras

\section{PENDAHULUAN}

Banyak keperluan dan kepentingan yang didapat dari foto/bitmap dalam aktifitas seharihari sebagai dokumen kenangan dan dapat mengenang atau sebagai kenang-kenangan mewakili suatu peristiwa-peristiwa yang penting. Banyak gambar yang telah dioleh dan dimodifikasi dalam rangka untuk memperbaiki kualitas gambar, untuk mengubah dan mengatur gambar sesuai dengan keinginan bahkan gambar dapat dimodifikasi dengan beberapa gambar yang dapat dipadukan sehingga menjadi suatu gambar yang berbeda dari sumbernya. Bertitik tolak dari modifikasi gambar yang dapat dipadukan dengan gambar yang lain maka bagaimana untuk membedakan bahwa suatu gambar terlah terjadi kontaminasi melalui perubahan pixel yang ada sehingga dapat dicari nilai-nilai deviasi/penyimpangan gambar dari yang awal dengan gambar yang telah diubah dengan bentuk mapun pewarnaannya. 


\section{TINJAUAN PUSTAKA}

a. Gambaran digital dapat diperoleh dengan beberapa cara, Pertama metode dengan photograph melalu foto dan kedua dengan mengambil gambar dengan menggunakan scanner printer. Dalam format semua gamabar digital dalam bentuk bitmap menggambarkan cara yang sama walaupun berbeda sumber aslinya dan memperhatikan parameter utama yang digunakan mendiskripsikan gambar digital, dengan teknik dan standar kompres. Gambar dapat dengan grayscale atau warna. Tampilan gambar pada monitor komputer banyak berupa titik-titik kecil. Ada titik-titik kecil pada elemen gambar yang disebut pixels. Ada sejumlah angka pixel baik garis horisontal mapun garis vertikal. Berbeda pixel boleh jadi berbeda kecerahan/brightness atau intensitasnya (Guojun Lu:28).

b. Ada beberapa jumlah rata-rata kualitas gambar yang dapat didiskripsikan. Bagaimana parameter dapat diketahui, Ketika ukuran image dan pixel lebar diketahui dengan data $D$ sehingga $D=x y b$

Ketika $\mathrm{x}$ jumlah pixel per garis horisontal dan y adalah jumlah garis vertikal dan $\mathrm{b}$ adalah jumlah bit per pixel maka contoh image 512 pixel ada 512 garis dengan kedalama pixel 24 bits sehingga jumlah data $D$ keseluruhan adalah $D=512^{*} 512^{*} 24$ bits $=768 \mathrm{~KB}$ (Guojun Lu:29.

c. Memperkenalkan gambar mentah dan menyediakan suatu definisi abstrak gambar mentah kemudian memperkenalkan perubahan bentuk gambar yang mengkonversikan gambar mentah ke dalam suatu format yang dimampatkan, sebagai contoh bentuk standar seperti GIF, JPEG, TIFF (V.S. Subrahmanian:38).

\section{METODE PENELITIAN}

1. Studi Literatur

Penulis mencari sumber pustaka atau dokumen untuk mempelajari permasalahan seperti teori Digital images, sehingga penulis memahami konsep pixel dengan indeks pada pixelx, pixely, pixelx dan pixel y mapun nilai pada pixelxy.

2. Analisa dan perancangan

Menggunakan analysis data pixel suatu gambar yang dapat diolah dengan melihat data rata-rata pada pixel horisontal dan pixel vertikal.

\section{HASIL DAN PEMBAHASAN}

Perubahan pixel dapat dianalisa dengan memgidentifikasikan data pada pixel baik pada gambar asli, gambar grayscale mapun gambar yang telah termodifikasi atau gambar yang telah dirubah.

Pada pembuatan tabel mengidentifikasian pixel di simpan dalam suatu field dan record yang ada pada tabel yaitu tabel tfotopixel dan tabel tfotohitung

Tabel 1. Deteksi foto pixel dengan nama tabel tfotopixel

\begin{tabular}{|l|l|l|l|l|}
\hline Name Fields & Type Data & Size & Constraint & Keterangan \\
\hline Nomorurut & number & 10 & Primary Key & \\
\hline Namafile & Text & 50 & Foreign Key & \\
\hline Posisix & Number & 10 & & \\
\hline Posisiy & Number & 10 & & \\
\hline Posisixy & Number & 10 & & \\
\hline Pixelx & Number & 10 & & \\
\hline Pixely & Number & 10 & & \\
\hline
\end{tabular}


Pada penyimpanan data pixel dapat dibaca melalui analisa data pixel dan letak poisis $x$ sebaga sumbu horisontal dan posisi y sebagai sumbu vertikal yang bertemu satu titik tersebut membentuk suatu pixel $x$ dan pixel $y$.

Tabel tersebut akan menampung data pada posisi pixel $\mathrm{x}$, pada posisi pixel $\mathrm{y}$, posisi pixelxy dan posisi nilai pixel $x$ dan $y$.

Tabel 2. Hitung dengan tabel tfotohitung

\begin{tabular}{|l|l|l|l|l|}
\hline Name Fields & $\begin{array}{l}\text { Type } \\
\text { Data }\end{array}$ & Size & Constraint & Keterangan \\
\hline Namafile & Text & $\mathbf{3 0}$ & & Dokumen nama file \\
\hline Dokumen1 & Text & $\mathbf{5 0}$ & & \\
\hline ratapixelxy & Number & 10 & & \\
\hline ratapixelx & Number & 10 & & \\
\hline ratapixely & Number & 10 & & \\
\hline ratanilaipixelxy & Number & 10 & & \\
\hline & & & & \\
\hline
\end{tabular}

Setelah data tersebut didapat maka langkah selanjutnya dalah mencari nilai rata-rata dari data sampling titik / dot pixel dengan sampling $100 \times 100$ maka di dapat data dengan disimpan dalam suatu tabel tfotohitung pada rata-rata pixelx disimpan pada data ratapixelx, pada data rata-rata pixely disimpan dalam suatu data ratapixely dan rata-rata pixelxy disimpan dalam field ratapixelxy serta nilai dari pixelxy disimpan dalam ratanilaipixelxy pada tabel di atas. Pada proses awal maka data dibuka dengan open data pada program sebagai berikut :

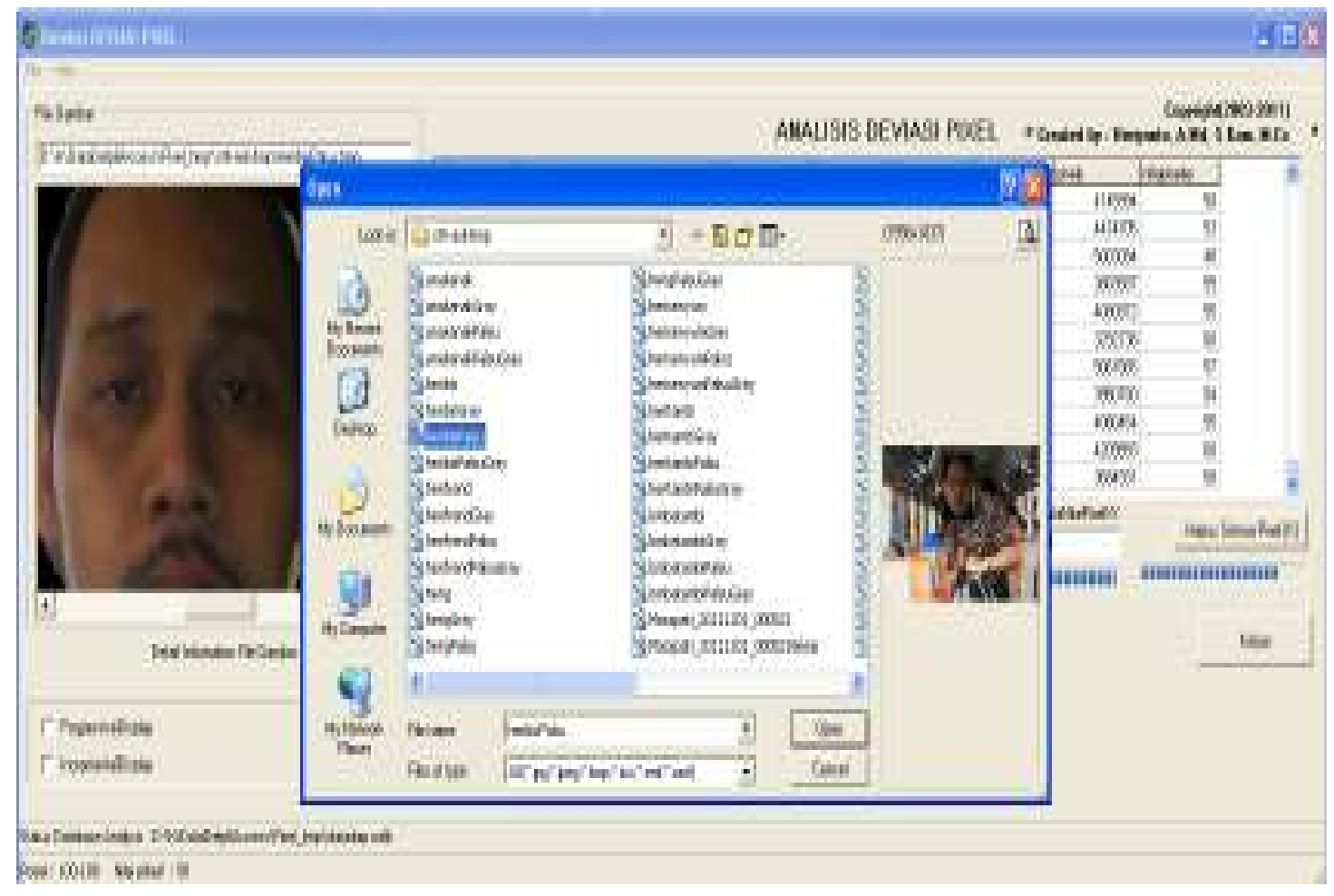

Gambar 1. Membuka file gambar bitmap dengan open folder

Setelah data gambar muncul maka mulai pengambilan pixel dengan cek pixel untuk samping $100 \times 100$ data pixel yang diambil sebagai berikut : 


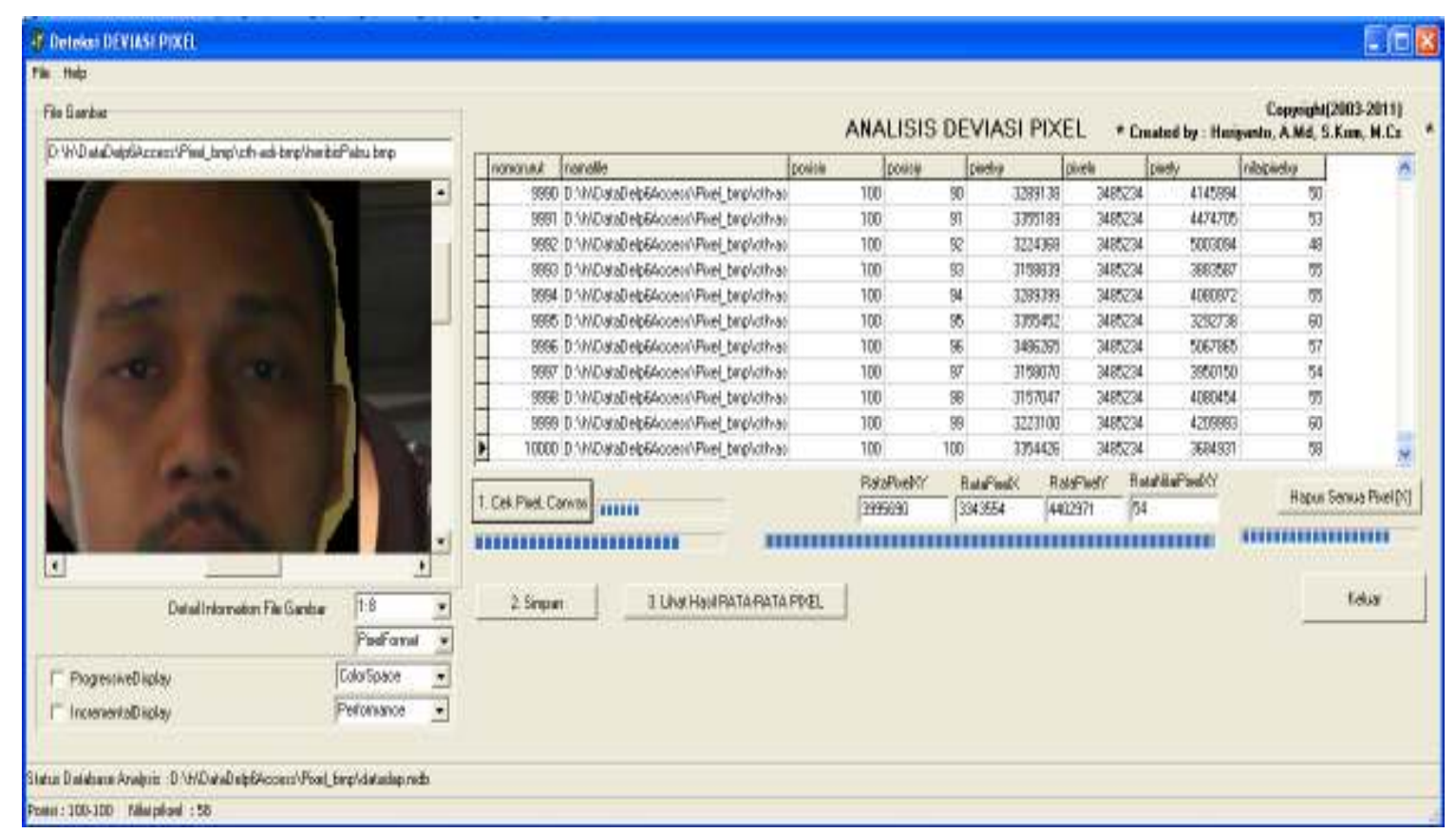

Gambar 2. deteksi cek pixel gambar

Dalam suatu proceder pixelcanvas sebagai berikut :

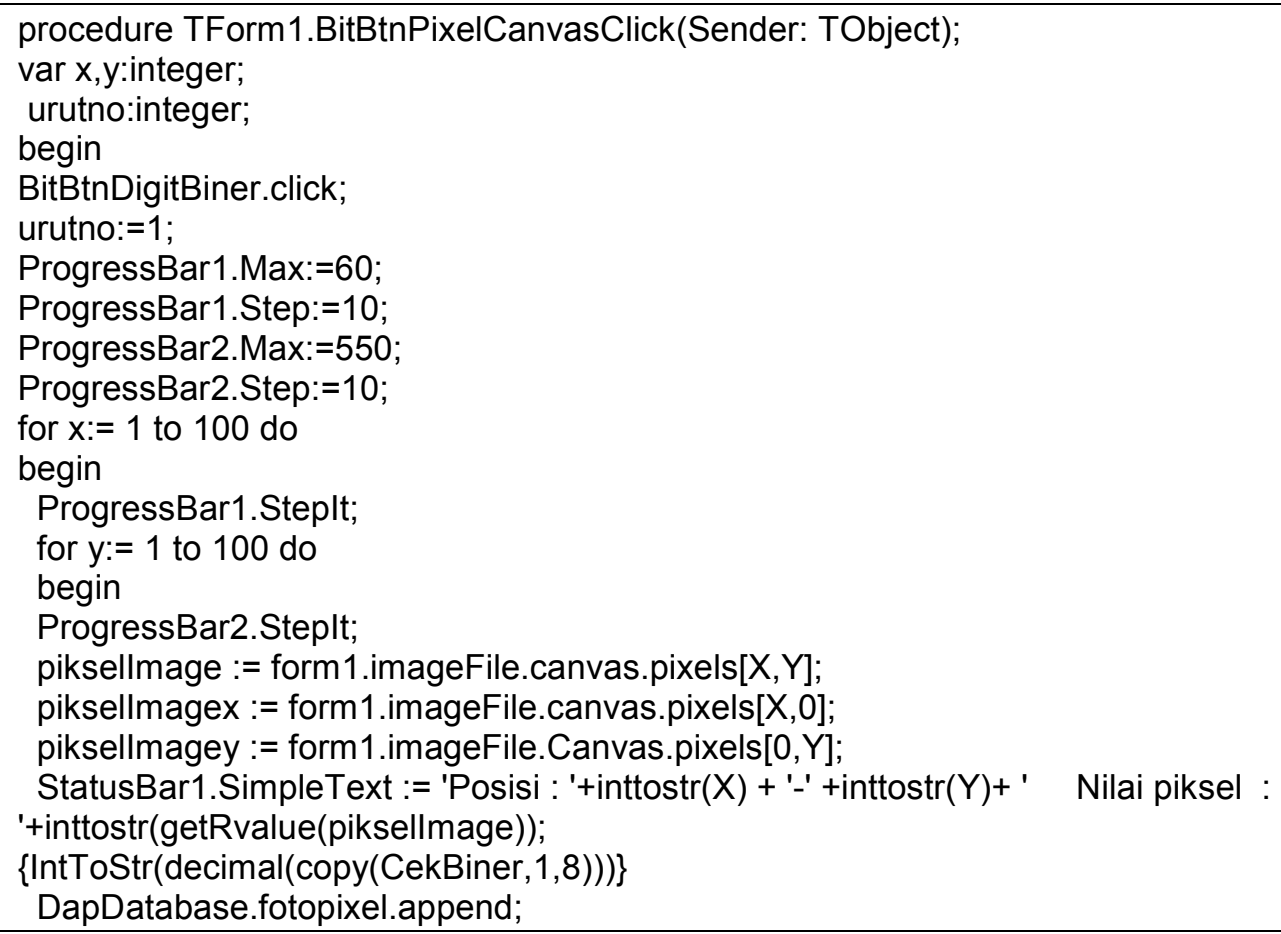




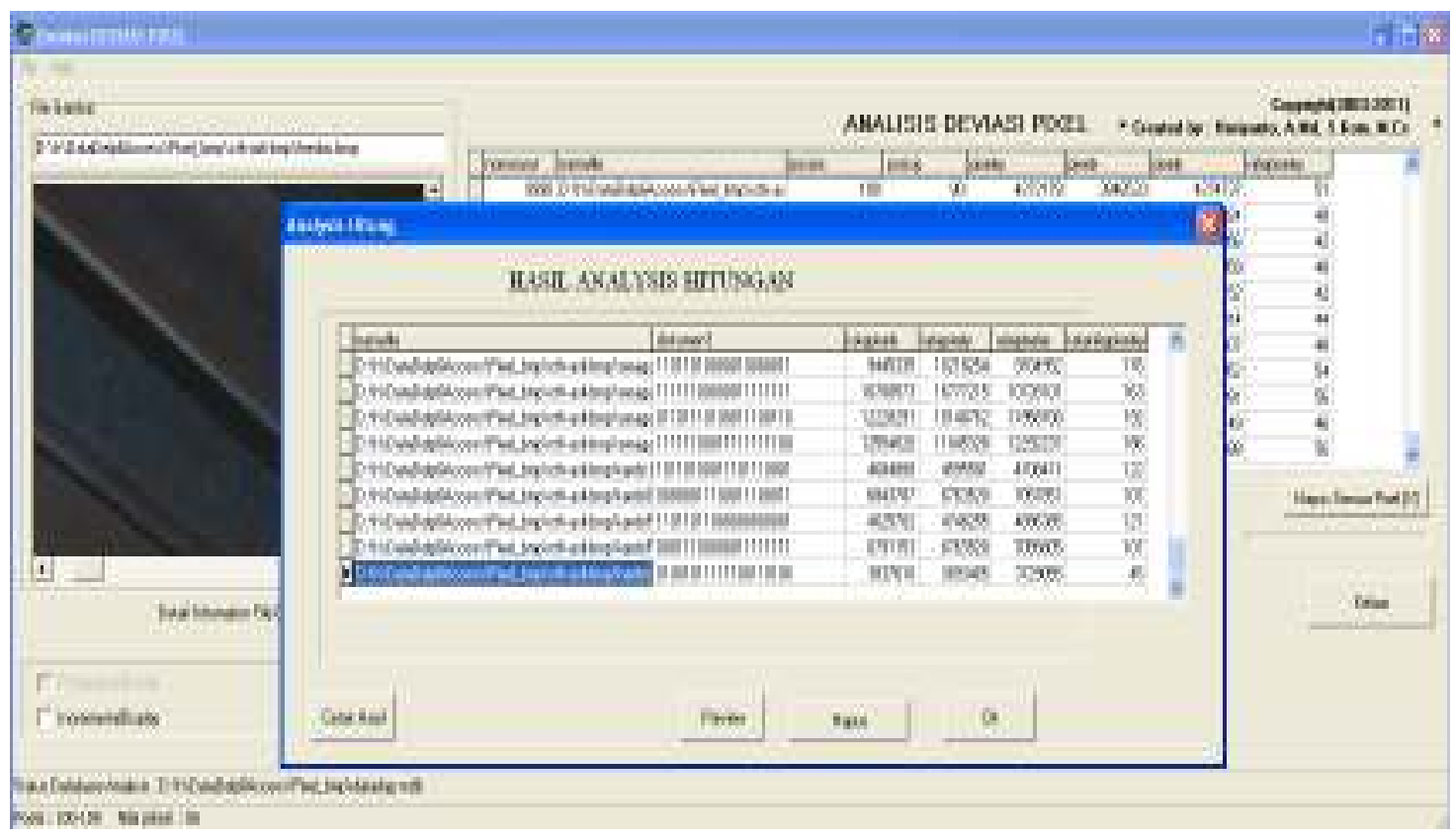

Gambar 3. Tampilan Hitungan Rate Pixel Analysis

Hasil tampilan sebagai berikut :

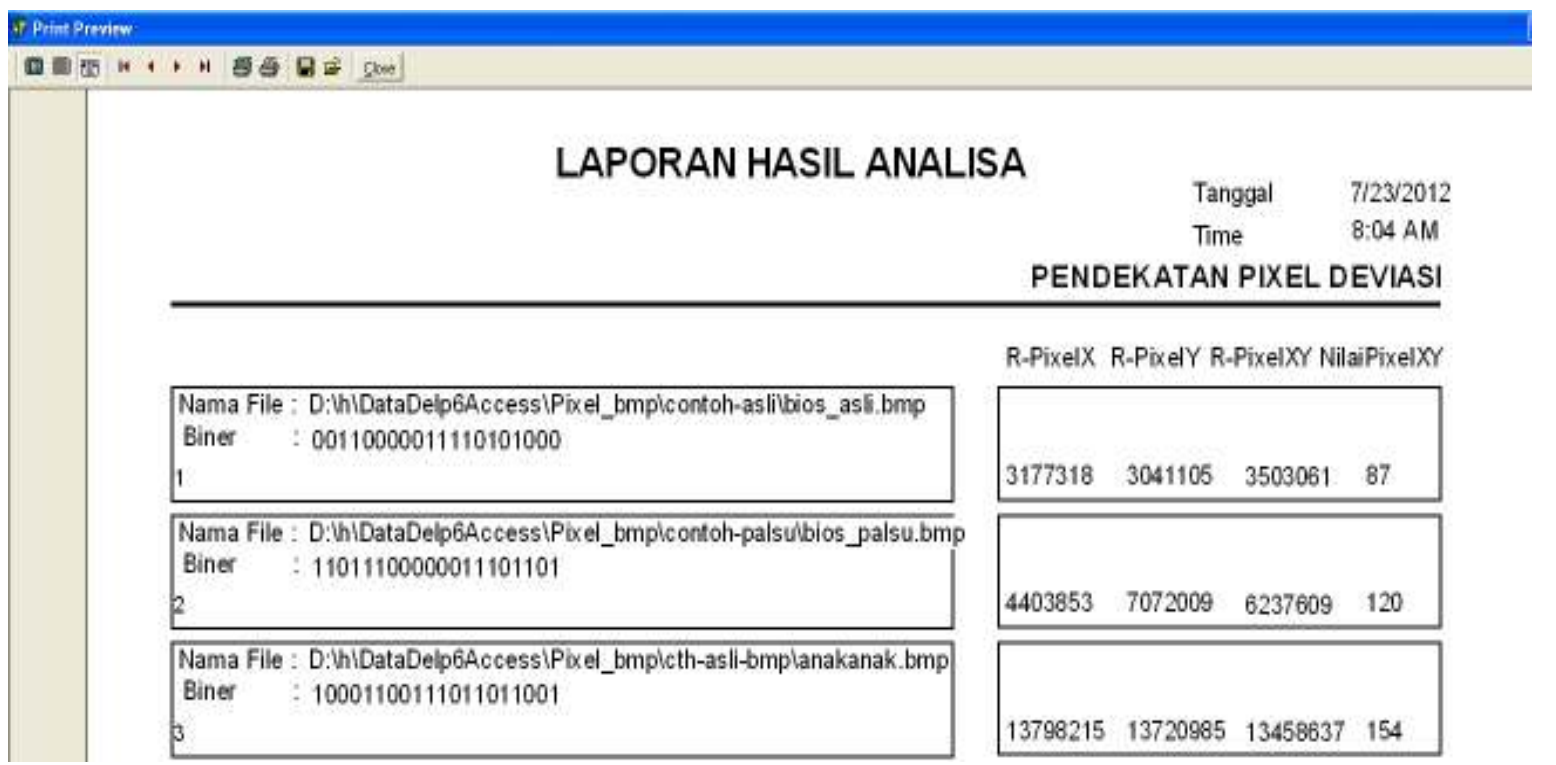

Gambar 4. Laporan Hasil Anlysis Pixel

Hasil analysis pixel yang didapat dengan masing-masing rata dapat di peroleh dengan Deviasi dapat dihitung dengan perhitungan pixel $x$ dan pixel y Hitung Deviasi pixelx - pixel y dengan selisih dan Hitung Selisih Deviasi :

$$
\text { (pixelx-pixely) x (selisih) }
$$


Tabel 3. Data analysa perhitungan perbandingan modikasi gambar, gray dan gambar asli

\begin{tabular}{|c|c|c|c|c|c|c|c|}
\hline namafile & ratapixelxy & Ratapixelx & pixelx-y & ratapixely & $\begin{array}{c}\text { ratanilai } \\
\text { pixelxy }\end{array}$ & selisih & $\begin{array}{l}\text { pixel x-y } \\
\text { * selisih }\end{array}$ \\
\hline $\begin{array}{l}\text { D:Ihlanalysisgmblkontra } \\
\text { s_bmplcth-asli- } \\
\text { bmplanakanak.bmp }\end{array}$ & 13458637 & 13798215 & 77230 & 13720985 & 154 & 12 & 926760 \\
\hline $\begin{array}{l}\text { D:Ihlanalysisgmblkontra } \\
\text { s_bmplcth-asli- } \\
\text { bmplanakanakGray.bm } \\
\text { p }\end{array}$ & 10955902 & 11259814 & 97374 & 11162440 & 166 & 0 & 0 \\
\hline $\begin{array}{l}\text { D:Ihlanalysisgmblkontra } \\
\text { s_bmplcth-asli- } \\
\text { bmplanakanakPalsu.bm } \\
\text { p }\end{array}$ & 11868667 & 12758820 & 855005 & 13613825 & 135 & 31 & $\begin{array}{r}2650515 \\
5\end{array}$ \\
\hline & & & 0 & & & & 0 \\
\hline $\begin{array}{l}\text { D:Ihlanalysisgmblkontra } \\
\text { s_bmplcth-asli- } \\
\text { bmplheribis.bmp }\end{array}$ & 3729055 & 3837610 & 144145 & 3693465 & 45 & 4 & 576580 \\
\hline $\begin{array}{l}\text { D:Ihlanalysisgmblkontra } \\
\text { s_bmplcth-asli- } \\
\text { bmplheribisGray.bmp }\end{array}$ & 3263589 & 3218593 & 128954 & 3347547 & 49 & 0 & 0 \\
\hline $\begin{array}{l}\text { D:Ihlanalysisgmblkontra } \\
\text { s_bmplcth-asli- } \\
\text { bmplheribisPalsu.bmp }\end{array}$ & 3995690 & 3343554 & $\begin{array}{r}- \\
105941 \\
7\end{array}$ & 4402971 & 54 & 5 & 5297085 \\
\hline & & & 0 & & & & 0 \\
\hline $\begin{array}{l}\text { D:Ihlanalysisgmblkontra } \\
\text { s_bmplcth-asli- } \\
\text { bmplherifrend.bmp }\end{array}$ & 10736958 & 9686457 & 929774 & 8756683 & 131 & 1 & 929774 \\
\hline $\begin{array}{l}\text { D:Ihlanalysisgmblkontra } \\
\text { s_bmplcth-asli- } \\
\text { bmplherifrendGray.bmp }\end{array}$ & 8728237 & 7990559 & 532923 & 7457636 & 132 & & 0 \\
\hline $\begin{array}{l}\text { D:Ihlanalysisgmblkontra } \\
\text { s_bmplcth-asli- } \\
\text { bmplherifrendPalsu.bm } \\
\text { p }\end{array}$ & 10488651 & 9371438 & $\begin{array}{r}149377 \\
5 \\
\end{array}$ & 7877663 & 143 & 11 & $\begin{array}{r}1643152 \\
5 \\
\end{array}$ \\
\hline & & & 0 & & & & 0 \\
\hline $\begin{array}{l}\text { D:Ihlanalysisgmblkontra } \\
\text { s_bmplcth-asli- } \\
\text { bmplherig.bmp }\end{array}$ & 13394937 & 13436715 & $\begin{array}{r}134367 \\
15\end{array}$ & 0 & 196 & 4 & $\begin{array}{r}5374686 \\
0\end{array}$ \\
\hline $\begin{array}{l}\text { D:Ihlanalysisgmblkontra } \\
\text { s_bmplcth-asli- } \\
\text { bmplherigGray.bmp }\end{array}$ & 13171995 & 13212550 & $\begin{array}{r}131980 \\
76 \\
\end{array}$ & 14474 & 200 & & 0 \\
\hline $\begin{array}{l}\text { D:Ihlanalysisgmblkontra } \\
\text { s_bmplcth-asli- } \\
\text { bmplherigPalsu.bmp }\end{array}$ & 13394937 & 13436715 & $\begin{array}{r}134367 \\
15\end{array}$ & 0 & 196 & 4 & $\begin{array}{r}5374686 \\
0\end{array}$ \\
\hline & & & 0 & & & & 0 \\
\hline
\end{tabular}

Rata nilaipixelxy dengan grayscale berdekatan 154 dengan 166 dan selisih 12 
Tabel 4. Hasil Toleransi Deviasi Pixel dan Konstan

\begin{tabular}{|c|c|c|c|c|c|c|c|c|c|}
\hline selisih & $\begin{array}{l}\text { pixel } \\
\mathrm{x}-\mathrm{y} \text { * } \\
\text { selisih }\end{array}$ & $\begin{array}{l}\text { nilai } x \\
\text { selisih }\end{array}$ & $\begin{array}{l}\text { nilai } x \\
\text { selish/ } \\
\text { nilaigr }\end{array}$ & $\begin{array}{l}\text { nilaipi } \\
\text { xel xy } \\
+ \\
\text { selisi } \\
\text { h }\end{array}$ & HASIL1 & toleransi & $\begin{array}{l}\text { HASIL } \\
2\end{array}$ & konstan & namafile \\
\hline 12 & $\begin{array}{r}92676 \\
0 \\
\end{array}$ & 1848 & 11 & 165 & 176 & 89 & 178.03 & 77 & $\begin{array}{l}\text { D:Ihlanalysisgmblkontras } \\
\text { bmplcth-asli- } \\
\text { bmplanakanak.bmp }\end{array}$ \\
\hline 0 & 0 & 0 & & 166 & & 83 & & 83 & $\begin{array}{l}\text { D:Ihlanalysisgmblkontras } \\
\text { bmplcth-asli- } \\
\text { bmplanakanakGray.bmp }\end{array}$ \\
\hline 31 & $\begin{array}{r}26505 \\
155 \\
\end{array}$ & 4185 & 25 & 160 & 158 & 96 & 180.38 & 70 & $\begin{array}{l}\text { D:Ihlanalysisgmblkontras } \\
\text { bmplcth-asli- } \\
\text { bmplanakanakPalsu.bmp }\end{array}$ \\
\hline & 0 & 0 & & 0 & & 0 & & 0 & \\
\hline 4 & $\begin{array}{r}57658 \\
0\end{array}$ & 180 & 4 & 49 & 50 & 26 & 54.45 & 23 & $\begin{array}{l}\text { D:Ihlanalysisgmblkontras } \\
\text { bmplcth-asli- } \\
\text { bmplheribis.bmp }\end{array}$ \\
\hline 0 & 0 & 0 & & 49 & & 25 & & 25 & $\begin{array}{l}\text { D:Ihlanalysisgmblkontras } \\
\text { bmplcth-asli- } \\
\text { bmplheribisGray.bmp }\end{array}$ \\
\hline 5 & $\begin{array}{r}52970 \\
85 \\
\end{array}$ & 270 & 6 & 48 & 49 & 22 & 28.71 & 27 & $\begin{array}{l}\text { D:Ihlanalysisgmblkontras } \\
\text { bmplcth-asli- } \\
\text { bmplheribisPalsu.bmp }\end{array}$ \\
\hline & 0 & 0 & & 0 & & 0 & & 0 & \\
\hline 1 & $\begin{array}{r}92977 \\
4 \\
\end{array}$ & 131 & 1 & 132 & 132 & 66 & 144.34 & 66 & $\begin{array}{l}\text { D:Ihlanalysisgmblkontras } \\
\text { bmplcth-asli- } \\
\text { bmplherifrend.bmp }\end{array}$ \\
\hline & 0 & 0 & & 132 & & 66 & & 66 & $\begin{array}{l}\text { D:Ihlanalysisgmblkontras } \\
\text { bmplcth-asli- } \\
\text { bmplherifrendGray.bmp }\end{array}$ \\
\hline 11 & $\begin{array}{r}16431 \\
525 \\
\end{array}$ & 1573 & 12 & 131 & 130 & 60 & 140.88 & 72 & $\begin{array}{l}\text { D:Ihlanalysisgmblkontras } \\
\text { bmplcth-asli- } \\
\text { bmplherifrendPalsu.bmp }\end{array}$ \\
\hline & 0 & 0 & & 0 & & 0 & & 0 & \\
\hline 4 & $\begin{array}{r}53746 \\
860\end{array}$ & 784 & 4 & 200 & 200 & 102 & 400.77 & 98 & $\begin{array}{l}\text { D:Ihlanalysisgmblkontras } \\
\text { bmplcth-asli- } \\
\text { bmplherig.bmp }\end{array}$ \\
\hline & 0 & 0 & & 200 & & 100 & & 100 & $\begin{array}{l}\text { D:Ihlanalysisgmblkontras } \\
\text { bmplcth-asli- } \\
\text { bmplherigGray.bmp }\end{array}$ \\
\hline \multirow[t]{2}{*}{4} & $\begin{array}{r}53746 \\
860 \\
\end{array}$ & 784 & 4 & 200 & 200 & 102 & 400.77 & 98 & $\begin{array}{l}\text { D:Ihlanalysisgmblkontras } \\
\text { bmplcth-asli- } \\
\text { bmplherigPalsu.bmp }\end{array}$ \\
\hline & 0 & 0 & & 0 & & 0 & & 0 & \\
\hline
\end{tabular}

perubahan gambar pada pixel dinyatalan termodifikasi bila toleransi dan konstanta tidak banyak selisihnya pada tolernasi 89,83 (grayscale) dan konstanta 77 sangat mendekati.

\section{KESIMPULAN}

Pada proses pengambilan gambar yang terdiri dari pixel sebagai titik-titik koordinat bagi vertikal maupun horisontal. Gambar tersebut memuat pixel yang berupa data pixel x, data pixel $y$, data pixel xy dan nilai pixelxy dan diolah menjadi rata-rata dengan sampling 100x100 didapat masing-masing rata-rata pixelx, rata-rata pixey, rata-rata pixel $x y$ dan rata-rata nilai pixelxy menjadi suatu deviasi dengan menghitung selisih dari gambar asli, gambar grayscale dan gambar yang termodifikasi. Maka dengan rata-rata nilaipixelxy apabila berdekatan dengan grayscale dan toleransi mendekati grayscale maka gambar tersebut tidak termodifikasi. Sebaliknya apabila jauh dari grayscale maka gambar sudah dapat dipastikan termodifikas. 


\section{DAFTAR PUSTAKA}

Lu, G, 1999, Multimedia Database Manajemen Systems, Artech House, Inc Sanjaya, Dwi, 1997, "Bertualang dengan Struktur Data", J \& J Learning Yogyakarta, Andi Offset,

Silberschatz, K, 2005, Databases Systems Concept, $5^{\text {th }}$ ed, McGrawHill

Subrahmanian, V.S, Principles of Multimedia Databases System 